Illinois State University

ISU ReD: Research and eData

Theses and Dissertations

7-6-2018

\title{
What's so bad about hooking up?: Factors predictive of more positive perceptions following a hookup
}

Jade A. M. Spaulding

Illinois State University, jaspaul@ilstu.edu

Follow this and additional works at: https://ir.library.illinoisstate.edu/etd

Part of the Public Health Education and Promotion Commons

\section{Recommended Citation}

Spaulding, Jade A. M., "What's so bad about hooking up?: Factors predictive of more positive perceptions following a hookup" (2018). Theses and Dissertations. 912.

https://ir.library.illinoisstate.edu/etd/912

This Thesis is brought to you for free and open access by ISU ReD: Research and eData. It has been accepted for inclusion in Theses and Dissertations by an authorized administrator of ISU ReD: Research and eData. For more information, please contact ISUReD@ilstu.edu. 


\section{WHAT'S SO BAD ABOUT HOOKING UP?: FACTORS PREDICTIVE OF MORE POSITIVE PERCEPTIONS FOLLOWING A HOOKUP}

\section{JADE A. M. SPAULDING}

\section{Pages}

The purpose of the study was to examine factors predictive of a more positive perceptions following a hookup. The participants included 188 students from Illinois State University. Participants completed a demographics questionnaire, the Hookup Scale, the Rosenberg SelfEsteem Scale, the Sexual Self-Esteem Inventory, religiosity questions, attitudes toward hooking up questionnaire, emotional reactions to hooking up questionnaire, and the Social Academic, Romantic, and Sexual Hooking Up Reactions Scale. The current study found that participants who reported high global self-esteem, high sexual self-esteem, and positive attitudes toward hooking up reported less regret, more positive reactions, and fewer negative reactions following a hookup.

KEYWORDS: Hookup, Regret, Self-Esteem, Religion, Attitude, Positive 


\title{
WHAT'S SO BAD ABOUT HOOKING UP?: FACTORS PREDICTIVE OF MORE POSITIVE PERCEPTIONS FOLLOWING A HOOKUP
}

JADE A. M. SPAULDING

\author{
A Thesis Submitted in Partial \\ Fulfillment of the Requirements \\ for the Degree of \\ MASTER OF SCIENCE \\ Department of Psychology \\ ILLINOIS STATE UNIVERSITY
}

2018 
Copyright 2018 Jade A. M. Spaulding 


\section{WHAT'S SO BAD ABOUT HOOKING UP?: FACTORS PREDICTIVE OF MORE POSITIVE PERCEPTIONS FOLLOWING A HOOKUP}

JADE A. M. SPAULDING

COMMITTEE MEMBERS:

Marla Reese-Weber, Chair.

Raymond Bergner 


\section{ACKNOWLEDGMENTS}

I would like to thank my committee chair, Dr. Marla Reese-Weber for her constant support, motivation, and guidance throughout this process. Dr. Reese-Weber showed so much passion in my research as well my life and I am grateful to have had her as a mentor. I would also like to give a large thank you to my committee member Dr. Raymond Bergner. Dr. Bergner approached this project with enthusiasm and encouragement and I appreciated the opportunity of being able to work with him. Finally, I would like to thank Dr. Reese-Weber's lab team for helping collect and enter data.

J.A.M.S. 


\section{CONTENTS}

Page

ACKNOWLEDGMENTS

$\begin{array}{ll}\text { CONTENTS } & \text { ii }\end{array}$

TABLES

FIGURES

CHAPTER I: THE PROBLEM AND ITS BACKGROUND 1

CHAPTER II: LITERATURE REVIEW

Hooking Up 4

$\begin{array}{ll}\text { Self-Esteem } & 6\end{array}$

$\begin{array}{ll}\text { Religion } & 8\end{array}$

$\begin{array}{ll}\text { Attitudes toward Hooking Up } & 10\end{array}$

$\begin{array}{ll}\text { Emotional Reactions } & 10\end{array}$

$\begin{array}{ll}\text { Proposed Study } & 13\end{array}$

$\begin{array}{ll}\text { Hypotheses } & 14\end{array}$

CHAPTER III: RESEARCH METHODOLOGY 16

$\begin{array}{ll}\text { Participants } & 16\end{array}$

$\begin{array}{ll}\text { Instruments } & 17\end{array}$

$\begin{array}{ll}\text { Demographics } & 17\end{array}$

$\begin{array}{ll}\text { Hookup } & 17\end{array}$

$\begin{array}{ll}\text { Global Self-Esteem } & 18\end{array}$

$\begin{array}{lr}\text { Sexual Self-Esteem } & 18\end{array}$

$\begin{array}{ll}\text { Religion } & 19\end{array}$ 
Procedure 


\section{TABLES}

Table

Page

1. Means and Standard Deviations of the Current Study's Variables

2. Means and Standard Deviations of Reactions Following a Hookup Experience

3. Means and Standard Deviations of Gender on Regret and Hookup Reactions

4. Means and Standard Deviations of Hookup Behavior on Regret and Hookup Reactions

5. Means and Standard Deviations of Hookup Partner on Regret and Hookup Reactions

6. Correlation Coefficients for Regret and Hookup Reactions

7. Means and Standard Deviations of Subjective Religiosity on Regret and Hookup Reactions

8. Z Scores for Sexual Self-Esteem Being a Better Predictor than Global Self-Esteem 


\section{FIGURES}

Figure $\quad$ Page

1. Predicted model of the relationship between gender, hookup behavior, self-esteem, sexual self-esteem, religion, attitudes, and less regret, more positive, and fewer negative reactions following a hook up. 


\section{CHAPTER I: THE PROBLEM AND ITS BACKGROUND}

Autonomy is the ability to think for yourself, make your own decisions, and choose your own pathway (O’Donnell, Chang, \& Miller, 2013). Emerging adults, ages 18-25, are at a developmental stage where they are starting to exercise their autonomy, including behaviors such as exploring and experimenting with sexuality (Owen, Rhoades, Stanley, \& Fincham, 2010). "Hooking up" is one common form of sexual exploration (Grello, Welsh, \& Harper, 2006). It involves behaviors ranging from kissing to sexual intercourse with a partner with whom an individual is not in a current relationship. Empirical studies have found $65 \%$ to $78 \%$ prevalence rates among emerging adults, with $40 \%$ to $72 \%$ reporting hooking up in the past year (Fielder $\&$ Carey, 2010a; Garcia \& Reiber, 2008; Paul, McManus, \& Hayes, 2000). With such a relatively high prevalence rate, hooking up is often perceived as a common behavior among emerging adults (Worth \& Fisher, 2010). Most research on hooking up has focused on negative correlates of hooking up, such as reports of sexual victimization, low self-esteem, and high levels of regret (Eshbaugh \& Gute, 2008; Herold \& Mewhinney, 1993; Littleton, Tabernik, Canales, \& Backstrom, 2009). However, hooking up may be on the rise due to many perceived benefits of hooking up such as exploring and developing a sexual identity, and obtaining sexual gratification without the need for a committed partner (Kenney, Thadani, Ghaidarov, \& LaBrie, 2013). The study explored in more detail emerging adults' perceptions of positive correlates associated with hooking up.

This proposal will begin by defining "hookup" and discussing the variability of hookup behaviors. Two of the most common factors examined by researchers when studying hooking up have been gender and hookup experience (e.g., hookup behaviors performed, partner type). 
Owen and Fincham (2011) found that men had more positive and less negative emotional reactions compared to women following a hookup. Similarily, LaBrie, Hummer, Ghaidarov, Lac, and Kenney (2014) found that men were more likely than women to indicate that they would have performed more hookup behaviors (e.g., moving beyond kissing to sexual intercourse). These findings suggest that men seem to experience more positive perceptions of hookup experiences than women. Fielder and Carey (2010a) found that women who hooked up, but did not have penetrative sex during those hookups had higher self-esteem than women who engaged in penetrative sex hookups. Grello et al. (2006) also found that hookup behaviors, specifically penetrative hookups, have a negative effect on a person's mental health. Regarding hookup partner, Lewis, Granato, Blayney, Lostutter, and Kilmer (2012) found that hooking up with a stranger was negatively related to positive affect. Similarly, Snapp, Ryu, and Kerr (2015) found hookups with a previous partner were related to more positive and sexually satisfying hookups than those with an acquaintance. These findings suggest that hooking up with a friend may be related to a more positive hookup experience. The proposed study will examine how gender (being male), hookup behavior (nonpenetrative), and hookup partner (non-stranger) might promote perceptions of a positive hookup experience.

Previous research on hooking up has also examined the relationship between hookups and psychological functioning, including global self-esteem (Fielder \& Carey, 2010a; Paul \& Hayes, 2000; Vrangalova, 2015a). Research related to global self-esteem has been inconsistent, which may be because global self-esteem does not examine the specific aspect of self-esteem most associated with hooking up behaviors - sexual self-esteem. Limited research to date suggests that sexual self-esteem may be a better predictor of hookup experience than global selfesteem (Oattes \& Offman, 2007). The proposed study will examine the relationships between 
both global self-esteem and sexual self-esteem and hooking up. Specifically, I am interested in exploring whether high sexual self-esteem is related to a positive hookup experience.

Previous research on hooking up has also examined its relationship with religion, specifically a participant's subjective level of religiosity (Fielder \& Carey, 2010a; Manthos, Owen, \& Fincham, 2014; Penhollow, Young, \& Bailey, 2007). However, at least one study found that church attendance may be a better predictor of hookup behavior than subjective religiosity (Burdette, Ellison, Hill \& Glenn, 2009). The proposed study will examine the relationship between both subjective religiosity and church attendance and hooking up. Again, with a focus on positive outcomes, I am interested in exploring whether low religiosity and church attendance are related to perceptions of a positive hookup experience.

Finally, previous research on hooking up has examined its relationship with attitudes toward hooking up. Previous research has found that having more permissive sexual attitudes toward hooking up is associated with a greater likelihood of hooking up and having positive emotional reactions (Owen et al., 2010; Townsend \& Wasserman, 2011). The proposed study will examine the relationship between attitudes toward hooking up and positive correlates. Specifically, I am interested in exploring whether positive attitudes toward hooking up are related to perceptions of a positive hookup experience. 


\section{CHAPTER II: LITERATURE REVIEW}

The review of the literature will begin by discussing multiple aspects of hooking up, such as definitions, behaviors, and outcomes. The review will then discuss self-esteem, including both global and sexual self-esteem and their relationship to hooking up. Third, the review will discuss the relationship between religion and hooking up. Fourth, the review will discuss attitudes toward hooking up. The final section will discuss emotional reactions toward hooking up.

\section{Hooking Up}

Definitions of hooking up have varied across studies. Some definitions have been broader than others. For example, Fielder, Walsh, Carey, and Carey (2013) define hooking up as sexual interactions that occur outside of a committed romantic relationship. In contrast, other definitions have been more constrained. Paul et al. (2000) defined hooking up as a sexual encounter that occurs between individuals who are strangers or acquaintances, may or may not include sexual intercourse, and usually lasts one night. The inconsistency in definitions of hooking up may explain why findings have been so varied. For the purpose of this study, hookup will be defined as a sexual encounter between two people who are not romantic partners with some physical interaction that may or may not include sexual intercourse (Paul et al., 2000).

The definition of hooking up varies due to the wide range of behaviors that have been associated with the term hookup. Hooking up may include behaviors such as kissing, petting, oral sex, anal sex, mutual masturbation, or vaginal sex (Garcia \& Reiber, 2008). Not only do researchers have varying definitions of hookups, but participants also perceive a wide range of behaviors that constitute a hookup. When participants were asked to indicate what they perceived to be the most minimal sexual behavior to represent a hookup, $12 \%$ reported kissing, $65 \%$ 
reported making out, $13 \%$ reported petting, $9 \%$ reported oral sex, and $0.6 \%$ reported vaginal or anal sex (Victor, 2012). With a variety of definitions used by both researchers and participants regarding what constitutes a hookup, it is extremely important to make that distinction clear.

Hooking up has been found to be related to both positive and negative correlates. Most studies tend to report negative correlates of a hookup, such as, poor mental health (e.g. depression, low self-esteem), sexual victimization, and sexually transmitted infections (Claxton \& Van Dulmen, 2013; Eshbaugh \& Gute, 2008; LaBrie et al., 2014; Paul \& Hayes, 2002). Conversely, recent studies have found that participants report more positive emotional reactions (e.g., happy, desirable, and pleased) than negative emotional reactions (e.g., awkwardness, disappointed, and empty; Fielder \& Carey, 2010b; Owen \& Fincham, 2011; Owen, Quirk, \& Fincham, 2014; Snapp, et al., 2015; Strokoff, Owen, \& Fincham, 2015). However, there are few studies that examine what factors lead to perceptions of a positive hookup. Snapp et al. (2015) found that self-affirmation motives (e.g., to what extent do you typically hook up because it makes you feel more self-confident) and hookups with a previous hookup partner led to positive emotionality. Additionally, Owen et al. (2010) found participants who reported positive reactions to hooking up reported higher psychological well-being and a higher level of acceptance of hooking up than those with negative reactions. These findings imply that when a person is hooking up with a partner they are comfortable with, if the hookup instills self-confidence, if they have high psychological well-being, and a general acceptance of hooking up they are more likely to report perceptions of a positive hookup.

In sum, the proposed study will examine factors related to more positive perceptions of a hookup (see Figure 1). This will give future researchers better insight into what aspects of hooking up are related to positive hookup experiences. 


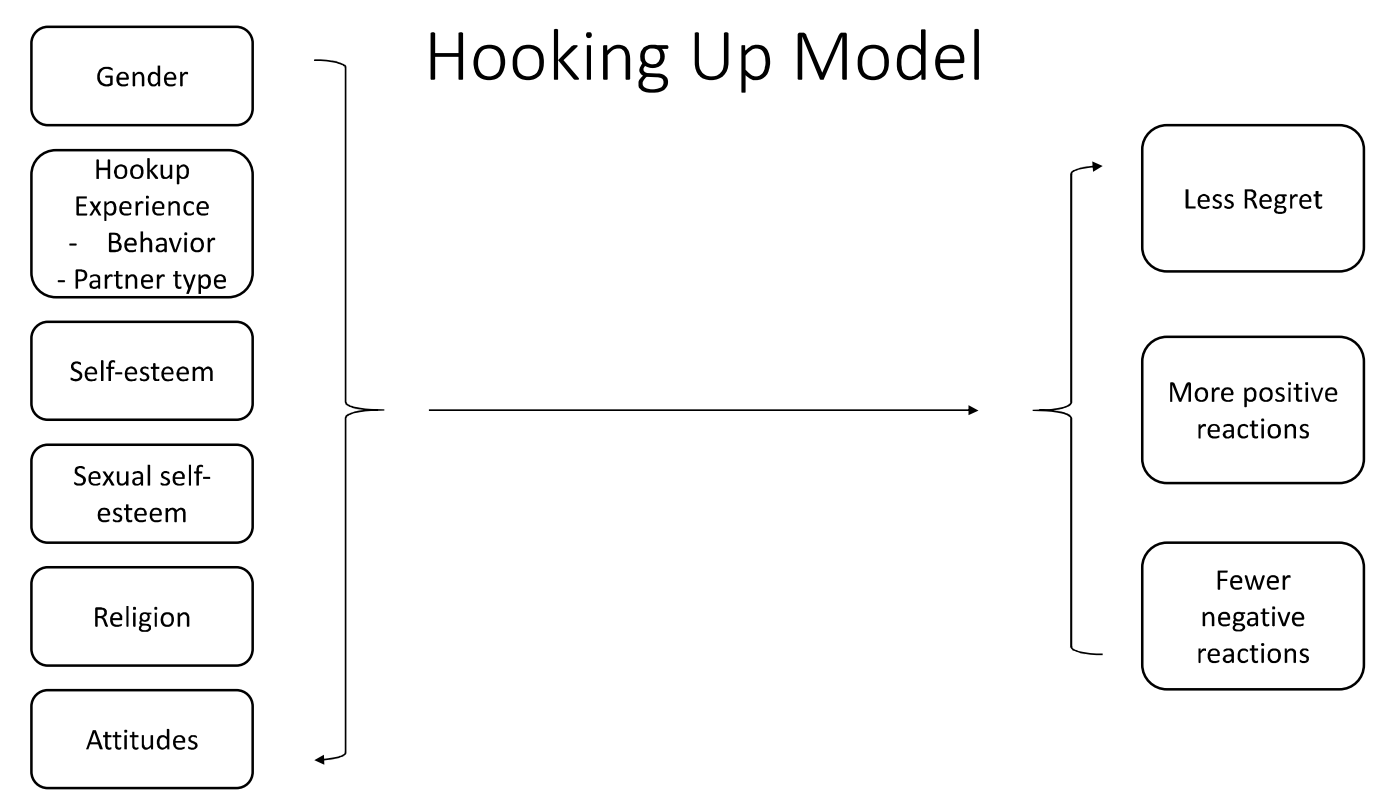

Figure 1: Predicted model of the relationship between gender, hookup behavior, self-esteem, sexual self-esteem, religion, attitudes and less regret, more positive, and fewer negative reactions following a hookup.

\section{Self-Esteem}

Global self-esteem is defined as a favorable or overall appraisal of worth toward oneself (Paul et al., 2000). The relationship between global self-esteem and hooking up has been examined extensively. Several studies have found global self-esteem to vary based on the sexual behaviors that take place during a hookup. Fielder et al. (2013) found that women with higher global self-esteem engaged in fewer hookups that involved performing oral sex. Another study found that women who hooked up during their first semester of college, but did not engage in penetrative sex during those hookups, had significantly higher global self-esteem than women who engaged in penetrative sex during their first semester of college (Fielder \& Carey, 2010a). 
Taken together, these studies suggest that women with higher global self-esteem may be less likely to engage in more serious sexual behaviors during a hookup (e.g., oral and vaginal sex). The difference may be because women with higher global self-esteem are more likely to hookup at their own pace, including deciding when to have oral and/or penetrative sex. Women with lower global self-esteem may feel less empowered or more pressured to have oral or vaginal penetrative sex while they are hooking up.

Previous research on the association between hooking up and global self-esteem also found that hooking up varies by gender. Herold and Mewhinney (1993) found that women reported significantly lower global self-esteem than men following a hookup. Men also have been found to have significantly higher global self-esteem the more partners they have hooked up with (Fielder \& Carey, 2010b). These findings suggest that men are more likely to experience higher global self-esteem in relation to hooking up compared to women.

Although there are extensive significant results on the relationship between hooking up and global self-esteem, there have been inconsistences. Several studies have found nonsignificant results for the relationship between hooking up and global self-esteem (Meier, 2007; Monahan \& Lee, 2008). Specifically, Vrangalova (2015a) found that global self-esteem was not related to whether a person had a hookup for either men or women. Similarly, another study found that global self-esteem was not a predictor of hooking up behaviors for either men or women (Barriger \& Velez-Blasini, 2013). This shift in findings could possibly be due to changing social norms and values regarding sex. Some men may have a lower global self-esteem due to the pressure of traditional gender roles or stereotypes and may engage in penetrative sex during a hookup, before they are actually ready, leading to lower global self-esteem. In contrast, 
women may not experience lower global self-esteem due to the changing progressive values about women having casual sex (Vrangalova, 2015b).

Some research has suggested that global self-esteem is too broad of construct to relate to sexual behaviors (Oattes \& Offman, 2007). Global self-esteem is comprised of many specific components. Sexual self-esteem is one of those components that may be important regarding hookup behaviors. Sexual self-esteem is defined as a person's reactions towards their appraisals of their sexual behaviors, thoughts, and feelings (Zeanah \& Schwarz, 1996). Research has suggested a relationship between sexual self-esteem and sexual behaviors. Shapiro and Schwarz (1997) found that women who had higher sexual self-esteem also had a higher frequency of sexual intercourse. Additionally, Menard and Offman (2009) found that high sexual self-esteem was positively correlated with sexual assertiveness and satisfaction. These findings imply that individuals who have high sexual self-esteem are likely to be assertive with their sexual needs and have pleasant experiences, which will only reinforce the behaviors that led to that positive sexual experience and continue to strengthen their sexual self-esteem. Hence, higher sexual selfesteem may be related to more positive emotional reactions following a hookup. The proposed study will examine both global self-esteem and sexual self-esteem to provide further insight into the connection both have with more positive perceptions following a hookup.

\section{Religion}

Today, fewer young adults are attending church services on a regular basis than in the past (Wuthnow, 2007). Some speculate this is because traditional religious views restrict sexual behavior, which could create incongruence in a person because hooking up is becoming more favorable among young adults (Brimeyer \& Smith, 2012). Eshbaugh and Gute (2008) found religious individuals were more likely to experience regret following a sexual experience than 
non-religious individuals. This sexual regret could be due to incongruency regarding what they want to do (i.e., engage in sexual behaviors) and what their religion views as appropriate (e.g., do not engage in sexual behaviors prior to marriage) (Brimeyer \& Smith, 2012).

Research on religion and hooking up has been inconclusive. Some studies found that there was no relationship between religion and hooking up (Fielder, \& Carey, 2010a; Bernston, Hoffman, \& Luff, 2014). However, several studies have found a significant relationship between subjective religiosity, how religious one individual considers him/herself to be, and hooking up. Specifically, the more religious beliefs a person has the less likely he/she is to hook up (Burdette, Christopher, Terrence, \& Norval, 2009; Manthos et al., 2014; Penhollow et al., 2007). In particular, the relationship between religion and hooking up is stronger for women. Owen et al. (2010) found that women who reported higher levels of religiosity had fewer hookup experiences than those who reported lower levels of religiosity. This relationship was not found for men. Additionally, women who reported high levels of religiosity were also less likely to perform or receive oral sex during a hookup than women who reported low levels of religiosity (Fielder et al., 2013). These findings could be due to the strict traditional values regarding sex established by the church, especially for women.

Most researchers studying the relationship between religion and hooking up have focused on subjective religiosity. However, frequency of a person's church attendance has been found to be a more powerful predictor of hooking up behaviors (Burdette et al., 2009). Studies have found that individuals who attended church more often while in college were less likely to hook up than those who did not attend church (Brimeyer \& Smith, 2012; Burdette et al., 2009). The proposed study will examine both subjective religiosity and church attendance as they relate to more positive perceptions following a hookup. 


\section{Attitudes toward Hooking Up}

Attitudes toward hooking up, specifically permissive sexual attitudes, is a psychosocial factor that recently has been studied in regards to predicting future hookup involvement. A person who holds permissive attitudes believes that casual sex, or sex in general, is a fun, nonserious act (Katz \& Schneider, 2013). First, research has shown that individuals who reported less religiosity, measured by both subjective religiosity and religious service attendance, had more permissive attitudes than individuals who reported more religiosity (Manthos et al., 2014). This finding may be due to the lack of religious beliefs that would not constrain their sexual beliefs. Research has also found gender differences in sexual attitudes, in particular, men tend to report more permissive sexual attitudes than women (Peterson \& Hyde, 2011). Similarly, previous research has found that men report more positive attitudes toward hooking up than women (Owen et al., 2010). Not surprisingly, having more permissive attitudes toward hooking up has been associated with a greater likelihood of hooking up as well as having more positive emotional reactions following the hookup (Owen et al., 2010; Townsend \& Wasserman, 2011). The proposed study will examine how attitudes toward hooking up are related to more positive perceptions following a hookup.

\section{Emotional Reactions}

Most research exploring emotional reactions to hookup experiences has focused on factors leading to high levels of regret (Lovejoy, 2015; Grello et al., 2006). Regret is when individuals feels negatively about themselves because of a decision they made or an action they took (Eshbaugh \& Gute, 2008). Because some emerging adults are expanding and exploring their sexuality, they run the risk of regretting their decisions. For example, Oswalt, Cameron, and 
Koop (2005) found that $72 \%$ of individuals regretted at least one time they engaged in a sexual activity.

Men and women have been found to have significant differences on level of regret following a hookup experience. Women have reported less comfort with hookup behaviors and less overall satisfaction with hooking up than men, leading to higher levels of regret (Lambert, Kahn, \& Apple, 2003; Shukusky \& Wade, 2012). According to Paul (2006), men may not experience regret from a hookup because they use the hookup to establish a dominant masculine image. History has shown that society values a man who is both physically and sexually dominant. Hence, sexual experiences, such as hookups, provide validation for men that they meet the expectations for masculinity. Women may experience regret after a hookup because they have been socialized that women having sex outside of a relationship is wrong. Hence, hookup experiences suggest women are not meeting the expectations of society to be more conservative in their sexual experiences.

The relationship between hooking up and emotional reactions has also been shown to vary by type of hookup behavior and hookup partner. Individuals who had penetrative sex and received oral sex with someone known to them less than 24 hours had a higher level of regret compared to participants who did not engage in those behaviors (Eshbaugh \& Gute, 2008). The behaviors performed in a hookup, such as penetrative or oral sex, may lead to higher levels of regret because they were more than the individual intended to perform or they were not comfortable performing those behaviors. Partner type, such as a stranger, may also lead to higher levels of regret because an individual may feel guilty for being intimate with a person they do not know. Lewis et al. (2012) found that hooking up with a stranger or casual acquaintance was negatively related to positive affect (i.e., happy, excited, desirable). This relationship could be 
due to uncertainty about their partner's hookup motives or not knowing their partner's sexual history, which could lead to more negative affect. Altogether, these findings suggest that when an individual engages in more serious sexual behaviors (e.g. penetrative sex, oral sex) with a person that they do not know well, the hookup experience is more likely to lead to higher levels of regret, and overall negative emotional reactions.

Emotional reactions, both positive and negative have been researched in relation to hooking up. However, negative emotional reactions have been more heavily focused on, even though research has shown that people experience more positive than negative emotions (Owen \& Fincham, 2011; Snapp et al., 2015). Negative emotional reactions have been associated with multiple domains of a person's life such as negative personal reactions, social/academic reactions, and sexual/romantic reactions (Owen et al., 2014). Men have been shown to have more positive and less negative emotional reactions to a hookup compared to women (Owen \& Fincham, 2011; Snapp et al., 2015). This may be because $32 \%$ of men were hoping for additional hookups following a hookup, while $43 \%$ of women were hoping for a traditional relationship following a hookup, which is not a common outcome of a hookup (Garcia \& Reiber, 2008).

In sum, most research has focused on factors of a hookup that lead to high levels of regret or negative emotional reactions (Grello et al., 2006; Lovejoy, 2015; Owen et al., 2014). The proposed study will examine the factors that lead to lower levels of regret, more positive, and fewer negative emotional reactions following a hookup. This research could benefit emerging adults who are already hooking up or intend to hook up by providing knowledge about what factors are related to lower levels of regret and positive emotional reactions. 


\section{Proposed Study}

There is a significant amount of research on hooking up. However, most of this research focuses on the negative aspects of hooking up. The proposed study examined what constitutes more positive perceptions following a hookup. The relationship between gender, type of hookup behaviors (e.g. kissing, oral sex, penetrative sex), type of partner (e.g. stranger, friend), global self-esteem, sexual self-esteem, subjective religiosity, church attendance, and attitudes toward hooking up was examined. The positive perceptions following a hookup experience were measured by less regret, more positive emotional reactions, and fewer negative emotional reactions.

The proposed study replicated previous research that found (a) men experience less regret following a hookup experience than women (Paul, 2006), (b) hooking up with a known partner is related to more positive hookup experiences (Snapp et al., 2015), and (c) not engaging in penetrative sex during a hookup is associated with more positive hookup experiences than engaging in penetrative sex during a hookup (Fielder \& Carey, 2010). In addition, the proposed study replicated findings regarding both global self-esteem and sexual self-esteem as predictors of hookup outcomes, as well as examined if sexual self-esteem is a better predictor of a positive hookup experience than global self-esteem. Similarly, the proposed study examined the relationship between both subjective religiosity and church attendance with hookup experience, as well as examined whether church attendance is a better predictor of positive hookup experience than subjective religiosity. Finally, the proposed study examined how positive attitudes towards hooking up are related to more positive hookup experiences. 


\section{Hypotheses}

H1: Men would experience less regret, more positive, and fewer negative hookup reactions compared to women.

H2: Participants who engaged in non-penetrative sex would experience less regret, more positive, and fewer negative hookup reactions compared to participants who engaged in penetrative sex.

H3: Participants who hooked up with a friend would experience less regret, more positive, and fewer negative hookup reactions compared to participants who hooked up with a stranger. H4: Participants with higher global self-esteem would experience less regret, more positive, and fewer negative hookup reactions compared to participants with lower global self-esteem.

H5: Participants with higher sexual self-esteem would experience less regret, more positive, and fewer negative hookup reactions compared to participants with lower sexual self-esteem.

H6: Participants who reported low subjective religiosity would experience less regret, more positive, and fewer negative hookup reactions compared to participants who reported high subjective religiosity.

H7: Participants who reported lower church attendance would experience less regret, more positive, and fewer negative hookup reactions compared to participants who reported higher church attendance.

H8: Participants with positive attitudes toward hooking up would experience less regret, more positive, and fewer negative hookup reactions compared to participants with negative attitudes toward hooking up.

H9: Church attendance would be a stronger predictor of less regret, more positive, and fewer negative hookup reactions than subjective religiosity. 
H10: Sexual self-esteem would be a stronger predictor of less regret, more positive, and fewer negative hookup reactions than global self-esteem. 


\section{CHAPTER III: RESEARCH METHODOLGY}

\section{Participants}

One hundred and eighty-eight participants were sampled from Illinois State University. The sample was comprised of $84.9 \%$ females, $14.5 \%$ male, and $.5 \%$ other. The sample had a mean age of $19.43(S D=1.44)$. The sample consisted of $41.9 \%$ freshman, $27.4 \%$ sophomores, $19.4 \%$ juniors, $10.2 \%$ seniors, and $1.1 \%$ graduate students. The participants were $64 \%$ Caucasian, 17\% African American, 11.3\% Hispanic, 3.2\% Asian, and 4.3\% other. Participants identified as $94.6 \%$ heterosexual, $1 \%$ gay/lesbian, and $4.3 \%$ bisexual. Regarding relationship status, $54.3 \%$ were single, $43 \%$ were dating somone, $1.6 \%$ were living with a significant other, and $1.1 \%$ were married. Regarding religion, $31.2 \%$ reported being not religious, $58.6 \%$ reported being moderately religious, and $10.2 \%$ reported being very religious. The participants were $63.8 \%$ Christian, $15.1 \%$ had no religious beliefs, $11.9 \%$ were spiritual but not religious, $5.4 \%$ other, $1.6 \%$ Jewish, $1.1 \%$ Hindu, . $5 \%$ Buddhist, and .5\% Muslim. The sample attended a mean of 1.08 religious services in a typical month. Regarding participant's living arrangements, $.5 \%$ lived with their parents, $55.9 \%$ lived in residence halls, $2.2 \%$ lived in an apartment alone, $38.2 \%$ lived in an apartment or house with friends, $2.7 \%$ lived in an apartment or house with a romantic partner, and $.5 \%$ reported other. Regarding family status, $54.3 \%$ of participants' biological or adopted parents were currently married, $24.2 \%$ of participants biological or adopted parents were divorced, $15.1 \%$ of participants' parents were single, and $6.5 \%$ of participants reported other. The participants had an average of $2.38(S D=1.84)$ biological/adopted/step-siblings. The participants reported that $4.1 \%$ of their mothers had some high school, but no degree, $24.1 \%$ of their mothers had a high school degree, $19.4 \%$ of their mothers had gone to two years of college, $29.4 \%$ of their mothers had gone to four years of college, and $22.9 \%$ of their mothers had a 
graduate degree (master's degree or higher). The participants reported that $7.9 \%$ of their fathers had some high school, but no degree, $33.3 \%$ of their fathers had a high school degree, $19.2 \%$ of their fathers had gone to two years of college, $29.9 \%$ of their fathers had gone to four years of college, and 9.6\% of their fathers had a graduate degree (master's degree or higher).

\section{Instruments}

\section{Demographics}

Participants were asked general information such as gender, age, ethnic background, sexual orientation (e.g. heterosexual, gay lesbian, bisexual), relationship status (e.g. single, dating, living with significant other, married, divorced, separated, widowed), year in school, religious intensity, and religious affiliation.

\section{Hookup}

The Hookup Scale was designed by Paul et al. (2000) and employs the definition of a hookup as, "A sexual encounter between two people who are not romantic partners with some physical interaction that may or may not include sexual intercourse". Participants were asked to report if they had ever experienced a hookup and estimate how many times they had hooked up. If the participants reported that they had not hooked up, they did not answer the additional questions about hooking up. Participants who reported they had a hookup were asked questions about their most recent hookup experience. These questions included partner type and sexual acts performed. Partner type was determined by selecting stranger, acquaintance, friend, ex-partner, or specifying another type of individual. The current study only used stranger and friend. Based on a study by Furman and Shaffer (2011), sexual acts were rated as 1 = light acts (kissing, cuddling, making out), 2 = heavy acts (light petting, heavy petting, and dry sex), and $3=$ genital acts (oral sex, vaginal intercourse, and anal intercourse). The current study recoded the variables 
into two groups, non-pentrative sex (lights acts and heavy acts) and penetrative sex (genital acts). Finally, participants were asked to indicate their level of regret the day after and currently about their most recent hookup on a scale of 1 (no regrets) to 4 (a lot of regret).

\section{Global Self-Esteem}

The Rosenberg Self-esteem Scale, created by Rosenberg (1965), was used to measure global self-esteem. Each of the 10 items is rated from strongly disagree to strongly agree on a 4point Likert scale. Higher scores represent higher levels of global self-esteem. There has been high internal reliability found when examining global self-esteem, with a range of .85 to .90 (Adler \& Hendrick, 1991; Oattes \& Offman, 2007). In the present study, the alpha coefficient was .90 .

\section{Sexual Self-Esteem}

The Sexual Self-Esteem Inventory (Short Form) created by Zeanah and Schwarz (1996) was used to measure self-appraisals of sexual thoughts, feelings, and behaviors. Each of the 35 items is rated from strongly disagree to strongly agree on a 6-point Likert scale. There are five subscales that reflect various aspects of sexual self-esteem: skill and experience (e.g., I feel selfassured about my sexual abilities); attractiveness (e.g., I am pleased with my physical appearance); moral judgment (e.g., my sexual behavior falls in line with my moral values); control (e.g., I get what I want sexually when I want it); and adaptiveness (e.g., I feel good about sex in my life). There has been good internal consistency (Cronbach's alpha $=.92)$ for the overall sexual self-esteem score (Zeanah \& Schwarz, 1996). Although developed to assess women, subsequent research also found high internal consistency for men (Cronbach's alpha $=.96)$ (Squiers, 1998). In the present study, the Cronbach's alpha was .93 for women and .89 for men. 


\section{Religion}

Participants were asked two questions on the demographics questionnaire to measure their level of religion. First, to measure subjective religiosity, "How intense are your current religious beliefs?" Participants answered on a 3-point Likert scale from not religious to very religious. Second, participants were asked "How many times do you attend a religious service in a typical month?” Manthos, et al. (2014) found a significant Pearson's correlation between the two items $(r=.85, p<.001)$. The current study found a significant Pearson's correlation between the two items $(r=.54, p<.001)$.

\section{Attitudes toward Hooking Up}

Attitudes toward hooking up was assessed by a 5-item measure created by Owen et al. (2010). Examples of the items include, "I feel more comfortable hooking up with someone than talking about my feelings with them" and "I feel that hooking up is a normal activity for college students". The items were rated from strongly agree to strongly disagree on a 7-point Likert scale. Higher scores indicated more favorable attitudes toward hooking up. These researchers found high internal consistency for this measure (Cronbach's alpha=.80). The current study found a Cronbach's alpha of .80 .

\section{Emotional Reactions to Hookup Experience}

Reactions toward a hookup experience was assessed by a modified measure created by Owen et al. (2010) and later adapted by Owen and Fincham (2011). Participants were asked how they currently felt about their last hookup experience regarding five positive reactions (happy, desirable, adventuresome, pleased, and excited) and five negative reactions (empty, confused, used, awkward, and disappointed) on a 5-point Likert scale from $1=$ not at all to $5=$ very much. The current study modified the measure by asking the participants to rate their feelings the day 
after their last hookup and currently regarding their last hookup. Higher scores indicated, respectively, more positive (for "happy', etc.) and negative (for "empty", etc.) emotional reactions toward hooking up. These researchers found good internal consistency for both positive and negative reactions (Cronbach's alpha $=.88$ and .82 , respectively). In the current study, positive and negative reactions the day of a participants most recent hookup had Cronbach's alphas of .88 and .87 , respectively. Positive and negative reactions currently about their most recent hookup had Cronbach's alphas of .93 and .89 , respectively.

Reactions toward a hookup experience were also assessed by the Social, Academic, Romantic, and Sexual Hooking Up Reactions Scale created by Owen et al. (2014). The measure is composed of three subscales: Sexual/Romantic Reactions (e.g., This hookup has taught me a lot about my sexual comfort with partners); Negative Reactions (e.g., Relationships with my friends have become strained due to this hookup - reverse scored); and Social/Academic Engagement (e.g., I feel more engaged in my school work after this hookup), however, for purposes of this study, only the Negative Reactions subscale was assessed. The 16 items were rated on a 5 -point Likert scale from $1=$ strongly disagree to $5=$ strongly agree. Higher scores indicated more positive emotional reactions toward their latest hookup experience. Good internal consistency has been found for the Negative Reactions subscale (Cronbach's alpha $=.84$ ). In the present study, there was also good internal consistency found for the Negative Reactions subscale (Cronbach's alpha $=.83)$.

\section{Procedure}

The current study recruited participants through the psychology SONA system. The requirements of the current study were that the participants be between 18-25 years old and had experienced a hookup. The study was administered in classrooms throughout Illinois State 
University. During the data collection sessions, participants first read and signed a paper version of the informed consent document. Once the participant signed and turned in their informed consent, they received a survey packet, including Demographics, the Hookup Scale, the Rosenberg Self-Esteem Scale, the Sexual Self-Esteem Scale, the Attitudes toward Hooking Up Scale, the Reactions Toward Hooking Up Scale, and the Social, Academic, Romantic, and the Sexual Hooking Up Reactions Scale. The survey packets were counterbalanced to control for order effects. Data collection sessions were separate for women and men to create a more comfortable environments.

The survey was completed in paper and pencil format. After completing the survey, participants placed their survey in a manila envelope, and placed that envelope in a box. Finally, each participant was given a debriefing statement including information on how to contact the researchers and community resources. 


\section{CHAPTER IV: RESULTS}

The current study found that $74.2 \%$ of participants had experienced a hookup, with an average of 5.26 hookups experienced. Of the $74.2 \%$ that had experienced a hookup, $70.1 \%$ reported engaging in a penetrative hookup and $29.9 \%$ reported engaging in a non-penetrative hookup. The sample also consisted of $54.2 \%$ of participants hooking up with a friend and $14.6 \%$ of participants hooking up with a stranger. The means and standard deviations of the current study's variables can be found on Table 1 and Table 2.

Hypothesis one stated that men would experience less regret, more positive, and fewer negative hookup reactions compared to women. A one-way ANOVA was conducted to compare gender and level of regret and reactions toward a hookup (see Table 3). Results indicated that there was not a significant difference between men and women's level of regret the day after their most recent hookup nor current level of regret about the most recent hookup. Results also indicated that there was not a significant difference between men's and women's negative reactions toward a hookup, positive reactions the day of the last hookup, negative reactions the day of the last hookup, positive reactions currently about the last hookup, and negative reactions currently about the last hookup. Hypothesis one was not supported.

Hypothesis two stated that participants who engaged in non-penetrative sex would experience less regret, more positive, and fewer negative hookup reactions compared to participants who engaged in penetrative sex. A one-way ANOVA was conducted to compare hookup behavior and level regret and reactions toward a hookup (see Table 4). Results indicated that there was not a significant difference between hookup behavior and regret the day after the most recent hookup nor current level of regret about the most recent hookup. Results also 
indicated that there was not a significant difference between hookup behavior and negative reactions toward a hookup, positive reactions the day of the last hookup, negative reactions the day of the last hookup, positive reactions currently about the last hookup, and negative reactions currently about the last hookup. Hypothesis two was not supported. 
Table 1

Means and Standard Deviations of the Current Study's Variables

\begin{tabular}{lc}
\hline & Mean $(S D)$ \\
\hline Global Self-esteem & $29.51(5.85)$ \\
Sexual Self-esteem & $146.19(27.06)$ \\
Subjective Religiosity & $1.79(.61)$ \\
Church Attendance & $1.08(1.60)$ \\
Attitudes Toward a Hookup & $18.20(6.73)$ \\
Negative Reactions Toward a Hookup & $29.62(5.07)$ \\
\hline
\end{tabular}


Table 2

Means and Standard Deviations of Reactions Following a Hookup Experience

\begin{tabular}{lll}
\hline & Day After Hookup & Currently \\
& Mean $(S D)$ & Mean $(S D)$ \\
\hline Regret & $1.93(1.00)$ & $1.86(1.05)$ \\
Happy & $3.40(1.06)$ & $3.04(1.24)$ \\
Desirable & $3.46(.98)$ & $3.08(1.19)$ \\
Adventuresome & $3.63(1.05)$ & $3.21(1.19)$ \\
Pleased & $3.45(1.06)$ & $2.96(1.28)$ \\
Excited & $3.31(1.13)$ & $2.89(1.25)$ \\
Empty & $2.18(1.19)$ & $2.08(1.23)$ \\
Confused & $2.52(1.38)$ & $2.33(1.36)$ \\
Used & $11.81(5.15)$ & $2.23(1.39)$ \\
Awkward & $2.20(1.31)$ & $2.38(1.33)$ \\
Disappointed & $2.55(1.28)$ & $2.45(1.39)$ \\
Positive Reactions Subscale & $17.24(4.39)$ & $15.18(5.43)$ \\
Negative Reactions Subscale & & \\
\hline & & \\
& &
\end{tabular}


Table 3

Means and Standard Deviations of Gender on Regret and Hookup Reactions

\begin{tabular}{lcccc}
\hline & $\begin{array}{c}\text { Men } \\
(n=23)\end{array}$ & $\begin{array}{c}\text { Women } \\
(n=122)\end{array}$ & $\begin{array}{c}\text { Total } \\
(n=155)\end{array}$ & $F$ \\
\hline Regret Day & $1.65(.65)$ & $1.98(1.05)$ & $1.93(1.00)$ & $F(1,143)=2.12, p=.15$ \\
Regret Current & $1.74(1.01)$ & $1.88(1.06)$ & $1.86(1.05)$ & $F(1,143)=.33, p=.56$ \\
Negative Reactions & $29.35(5.43)$ & $29.63(5.03)$ & $29.59(5.08)$ & $F(1,154)=.06, p=.81$ \\
Positive Day & $18.39(2.90)$ & $17.05(4.59)$ & $17.25(4.40)$ & $F(1,153)=1.83, p=.18$ \\
Negative Day & $10.04(2.99)$ & $12.09(5.40)$ & $11.79(5.16)$ & $F(1,153)=3.13, p=.08$ \\
Positive Current & $15.65(4.73)$ & $15.10(5.57)$ & $15.18(5.45)$ & $F(1,153)=.20, p=.65$ \\
Negative Current & $10.48(4.31)$ & $11.61(5.82)$ & $11.44(5.62)$ & $F(1,153)=.79, p=.38$
\end{tabular}

Note. The $n$ 's vary due to participants' willingness to respond to each question individually 
Table 4

Means and Standard Deviations of Hookup Behavior on Regret and Hookup Reactions

\begin{tabular}{lcccc}
\hline & $\begin{array}{c}\text { Non- } \\
\text { penetrative } \\
\text { sex } \\
(n=43)\end{array}$ & $\begin{array}{c}\text { Penetrative } \\
\text { sex } \\
(n=101)\end{array}$ & $\begin{array}{c}\text { Total } \\
(n=144)\end{array}$ & $F$ \\
\hline Regret Day & $1.95(1.02)$ & $1.93(1.00)$ & $1.94(1.01)$ & $F(1,142)=.02, p=.90$ \\
Regret Current & $1.70(.91)$ & $1.93(1.10)$ & $1.86(1.05)$ & $F(1,142)=1.50, p=.22$ \\
Negative Reactions & $30.37(4.40)$ & $29.73(5.23)$ & $29.92(4.99)$ & $F(1,142)=.49, p=.48$ \\
Positive Day & $17.97(4.29)$ & $17.11(4.36)$ & $17.37(4.34)$ & $F(1,142)=1.17, p=.28$ \\
Negative Day & $11.42(4.78)$ & $11.75(5.27)$ & $11.65(5.11)$ & $F(1,142)=.12, p=.73$ \\
Positive Current & $16.58(4.76)$ & $14.70(5.75)$ & $15.26(5.53)$ & $F(1,142)=3.56, p=.06$ \\
Negative Current & $10.42(4.86)$ & $11.60(5.89)$ & $11.24(5.61)$ & $F(1,142)=1.33, p=.25$
\end{tabular}

Note. The $n$ 's vary due to participants' willingness to respond to each question individually. 
Hypothesis three stated that participants who hooked up with a friend would experience less regret, more positive, and fewer negative hookup reactions compared to participants who hooked up with a stranger. A one-way ANOVA was conducted to compare hookup partner and level of regret and reactions toward a hookup (see Table 5). Results indicated that there was not a significant difference between hookup partner and regret the day after the most recent hookup nor current level of regret about the most recent hookup. Results also indicated that there was not a significant difference between hookup partner and negative reactions toward a hookup, positive reactions the day of the last hookup, negative reactions the day of the last hookup, positive reactions currently about the last hookup, and negative reactions currently about the last hookup. Hypothesis three was not supported. The relationship between stranger and non-stranger on level of regret and reactions toward a hookup was also examined and the results did not indicate a significant difference. 
Table 5

Means and Standard Deviations of Hookup Partner on Regret and Hookup Reactions

\begin{tabular}{lcccc}
\hline & $\begin{array}{c}\text { Stranger } \\
(n=21)\end{array}$ & $\begin{array}{c}\text { Friend } \\
(n=78)\end{array}$ & $\begin{array}{c}\text { Total } \\
(n=99)\end{array}$ & $F$ \\
\hline Regret Day & $2.19(1.21)$ & $1.86(.99)$ & $1.93(1.04)$ & $F(1,97)=1.69, p=.20$ \\
Regret Current & $1.95(1.12)$ & $1.83(1.04)$ & $1.86(1.05)$ & $F(1,97)=.21, p=.65$ \\
Negative Reactions & $30.52(5.17)$ & $30.44(4.32)$ & $30.45(4.49)$ & $F(1,97)=.01, p=.94$ \\
Positive Day & $17.62(4.27)$ & $17.83(4.25)$ & $17.83(4.23)$ & $F(1,97)=.04, p=.84$ \\
Negative Day & $11.57(5.78)$ & $11.32(4.68)$ & $11.38(4.90)$ & $F(1,97)=.04, p=.84$ \\
Positive Current & $15.95(6.26)$ & $15.74(5.32)$ & $15.79(5.50)$ & $F(1,97)=.02, p=.88$ \\
Negative Current & $11.86(6.67)$ & $10.66(5.07)$ & $10.91(5.43)$ & $F(1,97)=.81, p=.37$ \\
\hline
\end{tabular}


Hypothesis four stated that participants with higher global self-esteem would experience less regret, more positive, and fewer negative hookup reactions compared to participants with lower global self-esteem. A bivariate correlation was conducted to compare global self-esteem and level of regret and reactions toward a hookup (see Table 6). Results indicated all correlations were significant and in the expected direction. Higher global self-esteem was related to less regret the day after the hookup, less regret currently about the last hookup, more positive and fewer negative reactions the day after the hookup, more positive and fewer negative reactions currently about the last hookup, and fewer negative reactions toward a hookup. Hypothesis four was supported.

Hypothesis five stated that participants with higher sexual self-esteem would experience less regret, more positive, and fewer negative hookup reactions compared to participants with lower sexual self-esteem. A bivariate correlation was conducted to compare sexual self-esteem and level of regret and reactions toward a hookup (see Table 6). Results indicated all correlations were significant and in the expected direction. Higher sexual self-esteem was related to less regret the day after the hookup, less regret currently about the last hookup, more positive and fewer negative reactions the day after the hookup, more positive and fewer negative reactions currently about the last hookup, and fewer negative reactions toward a hookup. Hypothesis five was supported. 
Table 6

Correlation Coefficients for Regret and Hookup Reactions

\begin{tabular}{lccccccc}
\hline & $\begin{array}{c}\text { Regret } \\
\text { Day }\end{array}$ & $\begin{array}{c}\text { Regret } \\
\text { Current }\end{array}$ & $\begin{array}{c}\text { Negative } \\
\text { Reactions }\end{array}$ & $\begin{array}{c}\text { Positive } \\
\text { Day }\end{array}$ & $\begin{array}{c}\text { Negative } \\
\text { Day }\end{array}$ & $\begin{array}{c}\text { Positive } \\
\text { Current }\end{array}$ & $\begin{array}{c}\text { Negative } \\
\text { Current }\end{array}$ \\
\hline $\begin{array}{l}\text { Global } \\
\text { Self- } \\
\text { esteem }\end{array}$ & $-.19^{*}$ & $-.21^{*}$ & $.35^{* *}$ & $.16^{*}$ & $-.34^{* *}$ & $.27^{* *}$ & $-.36^{* *}$ \\
$\begin{array}{l}\text { Sexual } \\
\text { Self- } \\
\text { esteem }\end{array}$ & $-.32^{* *}$ & $-.37^{* *}$ & $.58^{* *}$ & $.34^{* *}$ & $-.53^{* *}$ & $.36^{* *}$ & $-.55^{* *}$ \\
$\begin{array}{l}\text { Religious } \\
\text { services } \\
\text { attended }\end{array}$ & .11 & -.05 & .06 & .08 & -.12 & .09 & -.12 \\
$\begin{array}{l}\text { Attitudes } \\
\text { toward a } \\
\text { hookup }\end{array}$ & $-.29 * *$ & $-.26^{* *}$ & .10 & $.34 * *$ & $-.25^{* *}$ & $.24 * *$ & $-.22^{* *}$ \\
\hline
\end{tabular}

Note. ${ }^{*} p<.05,{ }^{* *} p<.01$. The full correlation table can be acquired by contacting the author. 
Hypothesis six stated that participants who reported low subjective religiosity would experience less regret, more positive, and fewer negative hookup reactions compared to participants who reported high subjective religiosity. A one-way ANOVA was conducted to compare subjective religiosity and level of regret and reactions toward a hookup (see Table 7). Results indicated that there were no significant differences between subjective religiosity and any of the variables measuring regret and reactions. Hypothesis six was not supported.

Hypothesis seven stated that participants who reported lower church attendance would experience less regret, more positive, and fewer negative hookup reactions compared to participants who reported higher church attendance. A bivariate correlation was conducted to compare church attendance and level of regret and reactions toward a hookup (see Table 6). Results indicated there were not significant correlations between church attendance and regret the day after their most recent hookup, current level of regret about their most recent hookup, negative reactions toward a hookup, positive reactions the day of the hookup, negative reactions the day of the hookup, current positive reactions toward their most recent hookup, and current negative reactions toward their most recent hookup. Hypothesis seven was not supported. 
Table 7

Means and Standard Deviations of Subjective Religiosity on Regret and Hookup Reactions

\begin{tabular}{|c|c|c|c|c|c|}
\hline & $\begin{array}{c}\text { Not } \\
\text { religious } \\
(n=48) \\
\end{array}$ & $\begin{array}{c}\text { Moderately } \\
\text { religious } \\
(n=83) \\
\end{array}$ & $\begin{array}{l}\text { Very } \\
\text { religious } \\
(n=14) \\
\end{array}$ & $\begin{array}{c}\text { Total } \\
(n=155)\end{array}$ & $F$ \\
\hline Regret Day & $1.69(.72)$ & $2.01(1.09)$ & $2.29(1.20)$ & $1.93(1.00)$ & $F(2,142)=2.61, p=.08$ \\
\hline Regret Current & $1.73(1.03)$ & $1.96(1.11)$ & $1.64(.63)$ & $1.86(1.05)$ & $F(2,142)=1.08, p=.34$ \\
\hline Negative Reactions & $30.20(5.36)$ & $29.24(4.97)$ & $29.67(4.81)$ & $29.59(5.07)$ & $F(2,153)=.58, p=.56$ \\
\hline Positive Day & $17.68(4.15)$ & $17.01(4.70)$ & $17.29(3.36)$ & $17.25(4.40)$ & $F(2,152)=.38, p=.69$ \\
\hline Negative Day & $11.54(5.15)$ & $11.80(5.35)$ & $12.53(4.19)$ & $11.79(5.16)$ & $F(2,152)=.21, p=.81$ \\
\hline Positive Current & $14.26(5.32)$ & $15.42(5.73)$ & $16.80(3.55)$ & $15.18(5.45)$ & $F(2,152)=1.47, p=.23$ \\
\hline Negative Current & $12.25(6.06)$ & $10.93(5.51)$ & $11.80(4.69)$ & $11.44(5.62)$ & $F(2,152)=.91, p=.41$ \\
\hline
\end{tabular}

Note. The $n$ 's vary due to participants' willingness to respond to each question individually. 
Hypothesis eight stated that participants with positive attitudes toward hooking up would experience less regret, more positive, and fewer negative hookup reactions compared to participants with negative attitudes toward hooking up. A bivariate correlation was conducted to compare attitude toward hooking up and level of regret and reactions toward a hookup (see Table 6). Most correlations were significant and in the expected direction. More favorable attitudes toward hooking up were related to less regret the day after the hookup, less regret currently about the last hookup, more positive and fewer negative reactions the day after the hookup, and more positive and fewer negative reactions currently about the last hookup. Attitudes toward a hookup were not significantly related to having fewer negative reactions toward a hookup. Hypothesis eight was partially supported.

Because neither church attendance nor subjective religiosity were significantly related to level of regret, hypothesis nine was not conducted.

Hypothesis ten stated that sexual self-esteem would be more strongly related to level of regret and reactions toward a hookup than global self-esteem. A Fisher $\mathrm{Z}$ transformation was conducted to determine if sexual self-esteem was more strongly related to level of regret, more positive, and fewer negative reactions toward a hookup than global self-esteem (see Table 8). Results indicated that sexual self-esteem did not have a significantly stronger correlation with regret the day after participants most recent hookup, current level of regret about participants most recent hookup, positive reactions the day of participants last hookup, and current positive reactions toward participants last hookup than global self-esteem. Results indicated that sexual self-esteem did have significantly stronger correlations with negative reactions toward a hookup, negative reactions the day of participants last hookup, and current negative reactions towards participants last hookup than global self-esteem. Hypothesis ten was partially supported. 
Due to the small sample of men in the current study, the hypotheses were also conducted using only women participants. Results did not differ. 
Table 8

Z Scores for Sexual Self-Esteem Being a Better Predictor than Global Self-Esteem

\begin{tabular}{lccc}
\hline & $\begin{array}{c}\text { Global } \\
\text { Self-Esteem }\end{array}$ & $\begin{array}{c}\text { Sexual } \\
\text { Self-Esteem }\end{array}$ & $\mathrm{Z}$ \\
\hline Regret Day & $-.19^{*}$ & $-.32^{* *}$ & $z=1.22, p=.22$ \\
Regret Current & $-.21^{*}$ & $-.37^{* *}$ & $z=1.56, p=.12$ \\
Negative Reactions & $.35^{* *}$ & $.58^{* *}$ & $z=-2.59, p=.01$ \\
Positive Day & $.16^{*}$ & $.34^{* *}$ & $z=-1.66, p=.10$ \\
Negative Day & $-.34^{* *}$ & $-.53^{* *}$ & $z=2.01, p=.05$ \\
Positive Current & $.27^{* *}$ & $.36^{* *}$ & $z=-.92, p=.36$ \\
Negative Current & $-.36^{* *}$ & $-.55^{* *}$ & $z=2.05, p=.04$ \\
\hline
\end{tabular}

Note. ${ }^{*} p<.05, * * p<.01$ 


\section{CHAPTER V: DISCUSSION}

\section{Overview of Current Study}

The purpose of the current study was to examine factors predictive of a more positive perceptions following a hookup. Although research on hooking up has been expanding, the focus has primarily been on the negative factors associated with hooking up (Napper, Montes, Kenney, \& LaBrie, 2016; Owen, Fincham, \& Moore, 2011). Research that focuses on what leads to positive experiences following a hookup may be beneficial to health providers and educators working with the rising number of young adults that are engaging in hookup behaviors. The current study examined the relationship between reactions toward hooking up and a number of variables, including self-esteem, gender, and religion. The study found that higher global selfesteem, higher sexual self-esteem, and positive attitudes toward hooking up are all significantly related to an individual experiencing less regret, more positive reactions, and fewer negative reactions following a hookup experience. With this information, we are better able to educate young adults on how to safely engage in hookup behaviors.

Hypothesis one stated that men would experience less regret, more positive, and fewer negative hookup reactions compared to women. The current study was unable to find a significant difference between gender on feelings of regret, positive reactions and negative reactions following a hookup. Research has shown significant differences between men and women on level of regret and emotional reactions following a hookup, with men experiencing less regret and fewer negative emotional reactions compared to women (Fisher, Worth, Garcia, \& Meredith, 2012; Paul, 2006). One reason the current study may not have found significant differences between gender may be due to the small sample size of men. 
Hypothesis two stated that participants who engaged in non-penetrative sex would experience less regret, more positive, and fewer negative hookup reactions compared to participants who engaged in penetrative sex. However, the current study was unable to find a significant difference in level of regret, positive reactions, or negative reactions following a hookup between those who reported engaging in non-penetrative sex during a hookup and those who reported engaging in penetrative sex during a hookup. Previous research has found that most individuals do not experience regret following a hookup, however certain aspects of hooking up are associated with regret more than others. Uecker and Martinez (2017) found that hookups involving vaginal intercourse were more likely to end in an individual experiencing regret following a hookup. One reason results in the current study on level of regret, positive reactions, and negative reactions following a hookup did not significantly differ by hookup behavior may be due the participants thinking only about their last hookup. Several studies that found a significant relationship between hookup behavior and reactions examined individual's perceptions about all of their hookup experiences (Fielder \& Carey, 2010a; Fielder et al., 2013; Shukusky, \& Wade, 2012). It would be beneficial for future research to examine the relationship between an individuals perceptions of their last hookup compared to their perceptions of all of their hookup experiences.

Hypothesis three stated that participants who hooked up with a friend would experience less regret, more positive, and fewer negative hookup reactions compared to participants who hooked up with a stranger. Similar to hypotheses one and two, the current study was unable to find a significant difference in level of regret, positive reactions, and negative reactions following a hookup between those who report a hookup with a friend and those who report a hookup with a stranger. Previous research has found that participants are less likely to report 
positive affect after a hookup with a stranger in comparison to a hookup with a friend (Lewis et al., 2012). One reason why there were not significant differences found in the current study may be due to attitudes on hooking up shifting. As more young adults endorse a permissive attitude toward hooking up, they may be expecting to hookup with a partner who is a stranger. Although participants choose to hook up with strangers, it is likely there were certain factors about the strangers that led participants to hookup with them and perceive a positive experience. It would be beneficial to examine specific factors within indivdiauls who hookup solely with strangers.

Hypotheses four and five were supported such that participants who reported higher global self-esteem and higher sexual self-esteem reported less regret, more positive reactions, and fewer negative reactions following a hookup compared to participants who reported lower global and sexual self-esteem. To examine this relationship further, hypothesis ten examined whether sexual self-esteem would be a stronger predictor of less regret, more positive and fewer negative hookup reactions than global self-esteem. The current study found that sexual selfesteem was a stronger predictor of fewer negative reactions following a hookup than global selfesteem. Previous literature on the relationship between global and sexual self-esteem and hooking up has been inconsistent. Several studies have found both significant and nonsignificant relationships between global and sexual self-esteem and several aspects of hooking up (Fielder et al., 2013; Monahan \& Lee, 2008; Shapiro \& Schwarz, 1997). The current study’s findings on global and sexual self-esteem indicate that both global and sexual self-esteem are important to understanding why some hookup experiences may be more positive than others. However, sexual self-esteem may be particularly important to those who have higher sexual selfesteem experiencing more positive hookups than those with lower sexual self-esteem. 
Hypotheses six and seven stated that participants who reported low subjective religiosity and lower church attendance would experience less regret, more positive, and fewer negative hookup reactions compared to participants who reported high subjective religiosity and higher church attendance. The current study found no differences in level of regret, positive reactions, or negative reactions following a hookup based on subjective religiosity or church attendance. Due to these non-significant results, hypothesis nine, which stated that church attendance would be a stronger predictor of less regret, more positive, and fewer negative hookup reactions than subjective religiosity, was not tested. Previous research has shown that individuals who report being subjectively more religious or attend church services on a more regular basis are less likely to hook up and more likely to experience regret following a hookup (Eshbaugh \& Gute, 2008; Burdette et al., 2009). Researchers suggest religion may be a protective factor from individuals engaging in hook up behaviors, but also possibly lead to feelings of shame for individuals if they have engaged in a hookup because it goes against their religious values (Brimeyer \& Smith, 2012). One reason the current study may not have found significant results based on subjective religiosity and lower church attendance may be due to the location of the study. There have been several studies that have found significant results between hooking up and religion in the South and Southeastern United States (Brimeyer \& Smith, 2012; Mathos et al., 2014; Owen et al., 2010), where religion may play a more influential role than in the Midwest, West, or East. It would be benficial for future research to explore the relationship between hooking up, religion, and location.

Hypothesis eight stated that participants with positive attitudes toward hooking up would experience less regret, more positive, and fewer negative hookup reactions compared to participants with negative attitudes toward hooking up. The current study found that having more 
favorable attitudes toward hooking up was related to less regret experienced currently and the day after participants last hookup. The study also found that having more favorable attitudes toward hooking up was related to having more positive and fewer negative reactions currently and the day after participants last hookup. These findings suggest that individuals who hold favorable attitudes are more likely to experience more positive and less negative hookup experiences. Current literature has shown that having more permissive attitudes about hooking up is related to having more positive reactions following a hookup (Townsend \& Wasserman, 2011). Results from the current study may be used to help predict emerging adults behaviors in relation to hooking up.

\section{Limitations and Future Research Ideas}

The current study found significant results contributing to the literature on hooking up. However, it is not without its limitations. For example, the current study was only able to sample a small number of men. Future research should aim to recruit more men for information on hooking up as previous research has shown significant differences between men and women on hooking up (Bradshaw, Kahn, \& Saville, 2010; Owen \& Fincham, 2011).

Consistent with most of the research on hookups, another limitation of the current study is that the participants were primarily Caucasian, heterosexual, college students. Future research that investigates a more diverse sample may find cultural differences regarding hookup experiences. For example, current research between heterosexual hookups and homosexual hookups has been shown to vary in different aspects. Homosexual individuals are more likely to meet their hookup partners in different contexts than heterosexual individuals, such as through the internet or personal ads, which increases the chance of a homosexual individual hooking up with someone that they do not know (Kuperberg \& Padgett, 2015). However the literature on 
homosexual hookups is sparse (Kuperberg \& Padgett, 2017), which indicates it should be further examined.

Future research should examine other variables related to the hookup experience not examined in the current study. For example, information about whether or not participants were sexually satisfied, the location of the hookup between them and their partner, and whether or not the participant felt pressured or coercied might also explain positive and negative reactions following a hookup.

Finally, future research should further investigate the relationship between religion and hooking up. The current study was unable to test whether church attendance was a better predictor of less regret and positive hookup reactions than subjective religiosity, due to hypotheses six and seven being non-significant. One study suggests that church attendance would be a better predictor, (Burdette et al., 2009), however additional evidence of this relationship is needed.

\section{Strengths and Contributions}

The current study has several strengths. The study's findings add to the expanding research on the relationship between emerging adults and several factors related to hooking up. In particular, the current study provided additional information on how having both higher global self-esteem and higher sexual self-esteem is related to individuals being more likely to experience a positive hookup, with sexual self-esteem being a stronger predictor than global selfesteem. To the author's knowledge, this was the first study to compare whether global selfesteem or sexual self-esteem was a better predictor of hookup experience. These findings advance literature by suggesting that future research on hooking up should include both global and sexual self-esteem as predictors of individuals' perceptions of a hookup. These findings are 
also beneficial in a clinical setting as well. One of the ways for sexual self-esteem to increase is to have an open discussion with emerging adults about difficult topics, including sex, hooking up, wants, and desires. Whether the discussion is with a parent, therapist, primary care physician, it is important to increase an emerging adults knowledge so they are better equipt to make responsible decisions for themselves.

Furthermore, it would be beneficial to examine whether certain aspects of sexual selfesteem are more predictive of hookup experiences than others. The Sexual Self-Esteem Inventory (Zeanah \& Schwarz, 1996) is made up of five different subscales, including skill and experience, attractiveness, control, moral judgement, and adaptiveness. Zeanah and Schwarz hypothesized that these five subscales are related to specific sexual experiences, which could lead two individuals who have the same overall sexual self-esteem but higher scores on different subscales, to have two very different hookup experiences.

To the author's knowledge, this was also the first study to examine individuals' reactions to their last hookup regarding both how they currently felt as well as how they felt the day after their last hookup experience. The current study found a similar pattern of results for both perceptions (day after and currently) that may suggest asking about both does not provide additional information. However, future research should continue to examine these various time frames to provide replication.

Consistent with previous research (Owen et al., 2010; Townsend \& Wasserman, 2011), the current study also provided additional information on how having more favorable attitudes about hooking up was related to less regret, more positive and fewer negative reactions following hookup experiences. Future research would benefit from investigating specific factors that lead 
an individual to develop positive attitudes toward hooking up, such as parental attitudes toward sex or level of sex education received.

Finally, the current study focused on positive factors related to hooking up. A large portion of the current literature is focused solely on negative factors predictive of a negative hookup experience. If more research were focused on positive factors predictive of positive hookup experiences, clinicians and educators would be able to better equip emerging adults on how to make healthier psychological and physical sexual decisions.

\section{Conclusion}

The present study examined the factors predictive of more positive perceptions following a hookup. Hooking up has been related to negative consequences, such as shame, regret, and depression (Littleton et al., 2009). However the current study focused on which factors led to a more positive hookup experience. Having a better understanding of which specific factors have an effect on emotional outcomes is beneficial for clinicians, health care providers, and adolescents or young adults themselves. The current study found that having positive attitudes toward hooking up, higher global self-esteem, and higher sexual self-esteem are all related to more positive perceptions of hookup experiences. If adolescents and young adults are better informed on sexual self-esteem and a wide range of attitudes toward hooking up, they may be more likely to have positive perceptions following a hookup. 


\section{REFERENCES}

Adler, N. L., \& Hendrick, S. S. (1991). Relationships between contraceptive behavior and love attitudes, sex attitudes, and self-esteem. Journal of Counseling \& Development, 70, 302308.

Barriger, M., \& Vélez-Blasini, C. J. (2013). Descriptive and injunctive social norm overestimation in hooking up and their role as predictors of hook-up activity in a college student sample. Journal Of Sex Research, 50, 84-94.

Bernston, M. A., Hoffman, K. L., \& Luff, T. L. (2014). College as context: Influences on interpersonal sexual scripts. Sexuality \& Culture: An Interdisciplinary Quarterly, 18, 149-165.

Bradshaw, C., Kahn, A. S., \& Saville, B. K. (2010). To hook up or date: Which gender benefits?. Sex Roles, 62, 661-669.

Brimeyer, T. M., \& Smith, W. L. (2012). Religion, race, social class, and gender differences in dating and hooking up among college students. Sociological Spectrum, 32, 462-473.

Burdette, M. A., Christopher E. G., Terrence H. D., \& Norval G. D. (2009). 'Hooking Up' at College: Does Religion Make a Difference? Journal for the Scientific Study of Religion $48,535-551$.

Claxton, S. E., \& Van Dulmen, M. H. M. (2013). Casual sexual relationships and experiences in emerging adulthood. Emerging Adulthood, 1, 138-150.

Eshbaugh, E. M., \& Gute, G. (2008). Hookups and sexual regret among college women. The Journal Of Social Psychology, 148, 77-89. 
Fielder, R. L., \& Carey, M. P. (2010a). Predictors and consequences of sexual 'hookups' among college students: A short-term prospective study. Archives Of Sexual Behavior, 39, $1105-$ 1119.

Fielder, R. L., \& Carey, M. P. (2010b). Prevalence and characteristics of sexual hookups among first-semester female college students. Journal of Sex and Marital Therapy, 36, 346-359.

Fielder, R. L., Walsh, J. L., Carey, K. B., \& Carey, M. P. (2013). Predictors of sexual hookups: A theory-based, prospective study of first-year college women. Archives Of Sexual Behavior, 42, 1425-1441.

Fisher, M. L., Worth, K., Garcia, J. R., \& Meredith, T. (2012). Feelings of regret following uncommitted sexual encounters in Canadian university students. Culture, Health, and Sexuality, 14, 45-57.

Furman, W., \& Shaffer, L. (2011). Romantic partners, friends, friends with benefits, and casual acquaintances as sexual partners. Journal of Sex Research, 48, 554-564.

Garcia, J. R., \& Reiber, C. (2008). Hook-up behavior: A biopsychosocial perspective. Journal Of Social, Evolutionary, And Cultural Psychology, 2, 192-208.

Grello, C. M., Welsh, D. P., \& Harper, M. S. (2006). No strings attached: The nature of casual sex in college students. Journal of Sex Research, 43, 255-267.

Herold, E. S., \& Mewhinney, D. K. (1993). Gender differences in casual sex and AIDS prevention: A survey of dating bars. Journal Of Sex Research, 30, 36-42.

Katz, J. \& Schneider, M. E. (2013). Casual hook up sex during the first year of college: Prospective associations with attitudes about sex and love relationships. Archives of Sexual Behaviors, 42, 1451-1462. 
Kenney, S. R., Thadani, V., Ghaidarov, T., \& LaBrie, J. W. (2013). First-year college women's motivations for hooking up: A mixed-methods examination of normative peer perceptions and personal hookup participation. International Journal Of Sexual Health, $25,212-224$.

Kuperberg, A. \& Padgett, J.E. (2015). Dating and hooking up in college: Meeting contexts, sex, and variation by gender, partner's gender, and class standing. Journal of Sex Research, $52,517-531$.

Kuperberg, A., \& Padgett, J. E. (2017). Partner meeting contexts and risky behavior in college students' other-sex and same-sex hookups. Journal Of Sex Research, 54, 55-72.

LaBrie, J. W., Hummer, J. F., Ghaidarov, T. M., Lac, A., \& Kenney, S. R. (2014). Hooking up in the college context: The event-level effects of alcohol use and partner familiarity on hookup behaviors and contentment. Journal Of Sex Research, 51, 62-73.

Lambert, T. A., Kahn, A. S., \& Apple, K. J. (2003). Pluralistic ignorance and hooking up. The Journal of Sex Research, 40, 129-133.

Lewis, M. A., Atkins, D. C., Blayney, J. A., Dent, D. V., \& Kaysen, D. L. (2013). What is hooking up? Examining definitions of hooking up in relation to behavior and normative perceptions. Journal of Sex Research, 50, 757-766.

Lewis, M. A., Granato, H., Blayney, J. A., Lostutter, T. W., \& Kilmer, J. R. (2012). Predictors of hooking up sexual behaviors and emotional reactions among U.S. College students. Archives Of Sexual Behavior, 41, 1219-1229.

Littleton, H. Tabernik, H., Canales, E. J., \& Backstrom, T. (2009). Risky situation or harmless fun? A qualitative examination of college women's bad hook-up and rape scripts. Sex Roles, 60, 793-804. 
Lovejoy, M. C. (2015). Hooking up as an individualistic practice: A double-edged sword for college women. Sexuality \& Culture: An Interdisciplinary Quarterly, 19, 464-492.

Manthos, M., Owen, J., \& Fincham, F. D. (2014). A new perspective on hooking up among college students: Sexual behavior as a function of distinct groups. Journal of Social and Personal Relationships, 31, 815-829.

Meier, A. M. (2007). Adolescent first sex and subsequent mental health. American Journal of Sociology, 112, 1811-1847.

Menard, A. D. \& Offman, A. (2009). The interrelationships between sexual self-esteem, sexual assertiveness and sexual satisfaction. The Canadian Journal of Human Sexuality, 18, 3545.

Monahan, K. C., \& Lee, J. M. (2008). Adolescent sexual activity: Links between relational context and depressive symptoms. Journal of Youth and Adolescence, 37, 917-927.

Napper, L. E., Montes, K. S., Kenney, S. R., \& LaBrie, J. W. (2016). Assessing the personal negative impacts of hooking up experienced by college students: Gender differences and mental health. Journal Of Sex Research, 53, 766-775.

Oattes, M. K. \& Offman, A. (2007). Global self-esteem and sexual self-esteem as predictors of sexual communication in intimate relationships. The Canadian Journal of Human Sexuality, 16, 89-100.

O’Donnell, S. L., Chang, K. B., \& Miller, K. S. (2013). Relations among autonomy, attribution style, and happiness in college students. College Student Journal, 47, 228-234.

Oswalt, S. B., Cameron, K. A., \& Koob, J. J. (2005) Sexual regret in college students. Archives of Sexual Behavior, 34, 663-669. 
Owen, J., \& Fincham, F. D. (2011). Young adults' emotional reactions after hooking up encounters. Archives of Sexual Behavior, 40, 321-330.

Owen, J., Fincham, F. D., \& Moore, J. (2011). Short-term prospective study of hooking up among college students. Archives Of Sexual Behavior, 40, 331-341.

Owen, J. J., Rhoades, G. K., Stanley, S. M., \& Fincham, F. D. (2010). “Hooking up” among college students: Demographic and psychosocial correlates. Archives of Sexual Behavior, 39, 653-663.

Owen, J., Quirk, K., \& Fincham, F. (2014). Toward a more complete understanding of reactions to hooking up among college women. Journal of Sex and Marital Therapy. Advance online publication.

Paul, E. (2006). Beer goggles, catching feelings, and the walk of shame: Myths and realities of the hook up experience. In D. C. Kirkpatrick, S. Duck, \& M. K. Foley (Eds.), Relating difficulty: The processes of constructing and managing difficult interaction (pp. 141160). Mahwah: Lawrence Erlbaum.

Paul, E. L., McManus, B., \& Hayes, A. (2000). 'Hookups': Characteristics and correlates of college students' spontaneous and anonymous sexual experiences. Journal Of Sex Research, 37, 76-88.

Paul, E. L., \& Hayes, K. A. (2002). The casualties of "casual"' sex: A qualitative exploration of the phenomenology of college students' hookups. Journal of Social and Personal Relationships, 19, 639-661.

Penhollow, T., Young, M., \& Bailey, W. (2007). Relationship between religiosity and "'hooking up" behavior. American Journal of Health Education, 38, 338-345. 
Peterson, J. L., \& Hyde, J. S. (2011). Gender differences in sexual attitudes and behaviors: A review of meta-analytic results and large datasets. Journal of Sex Research, 48, 149-165. Rosenberg, M (1965). Rosenberg self-esteem scale (RSE). Acceptance and Commitment Therapy. Measures Package, 61.

Shukusky, J. A. \& Wade, J. T. (2012). Sex differences in hookup behavior: A replication and examination of parent-child relationship quality. Journal of Social, Evolutionary, and Cultural Psychology, 6, 494-505.

Shapiro, B. \& Schwarz, J. 1997. Date rape: Its relationship to trauma symptoms and sexual self esteem. Journal of Interpersonal Violence, 12, 407-19.

Snapp, S., Ryu. E., Kerr, J. (2015). The upside to hooking up: College students' positive hookup experiences. International Journal of Sexual Health, 27, 43-56.

Squiers, L. B. (1998). Sexual self-esteem and its relationship to demographics, sexual history, relationship context, and condom use in college students. Dissertation Abstracts International Section A, 59, 1930.

Strokoff, J. Owen, J., \& Fincham, F. D. (2015). Diverse reactions to hooking up among U.S. university students. Archives of Sexual Behavior, 44, 935-943.

Townsend, J. M., \& Wasserman, T. H. (2011). Sexual hookups among college students: Sex differences in emotional reactions. Archives of Sexual Behavior, 40, 1173-1181.

Uecker, J. E. \& Martinez, B. C. (2017). When and why women regret sex in hookups more than men do: An analysis of the online college social life survey. The Sociological Quarterly, $58,470-494$.

Victor, E. (2012). Mental health and hooking up: A self-discrepancy perspective. New School Psychology Bulletin, 9. 
Vrangalova, Z. (2015a). Does casual sex harm college students' well-being? A longitudinal investigation of the role of motivation. Archives Of Sexual Behavior, 44, 945-959.

Vrangalova, Z. (2015b). Hooking up and psychological well-being in college students: Shortterm prospective links across different hookup definitions. Journal Of Sex Research, 52, 485-498.

Worth, K., \& Fisher, M. (2012). Review of hooking up: Sex, dating and relationships on campus. Journal of Social, Evolutionary, and Cultural Psychology, 4, 49-51.

Wuthnow, Robert. (2007). After the Baby Boomers: How Twenty- and Thirty-Somethings are Shaping the Future of American Religion. Princeton, NJ: Princeton University Press.

Zeanah, P .D., \& Schwarz, J.C. (1996). Reliability and validity of the sexual self-esteem inventory for women. Assessment, 3, 1-15. 


\section{APPENDIX A: INFORMED CONSENT}

Research Participant Informed Consent - APPLE

\section{PLEASE READ THIS DOCUMENT CAREFULLY. SIGN YOUR NAME BELOW ONLY IF YOU AGREE TO PARTICIPANT. YOUR SIGNATURE IS REQUIRED FOR PARTICIPATION IN THIS RESEARCH. YOU MUST BE AT LEAST 18 YEARS OF AGE TO PARTICIPATE.}

Description of the Study: This research study will ask you to answer several questions regarding your cognitive and emotional states, and your past childhood adolescent, and adulthood experiences. You will need a pen or pencil, the survey, and a manila envelope to complete the study. You will be asked to complete the survey, place it inside the manila envelope, and then place it in the box at the front of the room marked "Surveys".

Nature of Participation: You will spend approximately 45-60 minutes completing the survey measures.

Purpose of the Study: The purpose of the study is to examine how cognitive and emotional states of young adults are associated with specific past experiences, including adverse past experiences.

Possible Risks: There may be a risk of uncomfortable feelings and/or painful thoughts/memories when answering the survey questions. However, please note that you may drop out of the study at any time, or skip any questions you do not want to answer. Also, researchers will provide you with a list of local resources who can help you. If needed, researchers will take you to the Student Counseling Services building. Although code numbers will be used and no identifying information will be on your questionnaire packet, there is also a slight risk of loss of confidentiality.

Possible Benefits: This study will allow participants to contribute to the understanding of cognitive and emotional states among young adults as an outcome of past experiences. If you desire to be informed about the outcome of this study, you can contact the researcher through the information listed below

Compensation for your time: You will receive extra credit in a psychology course through the SONA system. You will receive extra credit simply by the virtue of coming to your appointment; you are free to withdraw your participation at any time without penalty.

Confidentiality: Your questionnaire packet has been assigned a code number that will protect your identity. This signed informed consent document will be kept separate from your questionnaire packet. All data will be kept in secure files, in accord with the standards of the University, Federal regulations, and the American Psychological Association. Finally, it is no individual person's responses that interest us; we are studying people in general.

Opportunities to Question: Any technical questions about this research may be directed to Dr. Marla Reese-Weber at (309) 438-3743. Any questions regarding your rights as a research participant or research-related injuries may be directed to ISU's Office of Research Ethics and Compliance (309) 438-2529. 
Opportunities to Withdraw at Will: Your participation is completely voluntary. If you decide now or at any point to withdraw this consent or stop participation, you are free to do so at no penalty to yourself. You are also free to skip questions you do not want to answer and continue participating without loss of benefits.

Opportunities to be Informed of Results: In all likelihood, the results will be fully available around the summer of 2018. If you wish to be told the results of this research, please contact Dr. Marla Reese-Weber at (309) 438-3743. She will either meet with you to discuss the results or direct you to a copy of the results. In addition, there is a chance that the results from this study will be published in a scientific psychology journal, which would be available in many libraries. In such an article, participants would be identified in general terms such as "college students".

I consent to participate in this study.

Signature

Date

Print Name

Date 


\section{APPENDIX B: DEMOGRAPHIC QUESTIONNAIRE}

1. Gender
a. Male
b. Female
c. Other (please specify)

2. Age:

3. Ethnic Background:
a. Asian/Asian-American
b. Black/African American
c. Hispanic/Latino
d. White/Caucasian
e. Other (please specify)

4. Sexual Orientation
a. Heterosexual (straight)
b. Gay
c. Lesbian
d. Bisexual
e. Other (please specify)

5. Relationship Status
a. Single
b. Dating someone
c. Living with significant other
d. Married
e. Divorced
f. Separated
g. Widowed
h. Other (please specify)

6. If Applicable: Year in School
a. Freshman
b. Sophomore
c. Junior
d. Senior
e. Graduate Student-Master's
f. Graduate Student-Doctorate

7. How intense are your current religious beliefs?
a. Not religious
b. Moderately religious 
c. Very religious

8. How many times have you attended a church service over the last month? time(s)

9. Current Living Arrangements

a. Live with parents

b. Live in the residence halls

c. Live in an apartment/house alone

d. Live in an apartment/house with friends

e. Live in an apartment/house with romantic partner

f. Other (please specify)

10. Family Status:

a. Biological/adopted parents are currently married (skip next question)

b. Biological/adopted parents are currently divorced

c. Single Parent

d. Other, please specify

11. Following the divorce of your biological/adopted parents, with whom did you live the majority of the time?
a. Mother
b. Mother and Step-father
c. Father
d. Father and Step-mother
e. Other, please specify

12. Mother/stepmother's Highest Education:

a. Some high school, but no degree

b. High School degree

c. Two years college

d. Four years college (Bachelor's degree)

e. Graduate Degree (Master's degree or higher)

13. Father/stepfather's Highest Education:

a. Some high school, but no degree

b. High School degree

c. Two years college

d. Four years college (Bachelor's degree)

e. Graduate Degree (Master's degree or higher)

14. How many biological/adopted/step-siblings do you have? 


\section{APPENDIX C: DEBRIEFING STATEMENT}

The purpose of the study is to examine if past sexual experiences are related to the cognitive and emotional states of young adults. We expect that individuals with histories of specific sexual experiences will have varying levels of self-esteem, relationship attachment, and life satisfaction compared to individuals without such experiences.

If after completing this study you are upset or would like to discuss your experiences, you may contact: Illinois State University's Student Counseling Services at (309) 438-3655 or http://counseling.illinoisstate.edu. The PATH crisis center for a referral at (309) 827-4005 or 1800-570-7284. The National Sexual Assault Hotline at 1-800-656-4673 or http://www.rainn.org/ Please remember that your responses are confidential and all data will be kept in secure files. If you have any questions regarding this study or would like more specific information regarding this study, please contact Dr. Marla Reese-Weber at (XXX)-XXX-XXXX; xxxx@ilstu.edu.You may also contact the graduate students conducting this study to satisfy a Master's Thesis in psychology, Kristen Silbert at xxxx@ilstu.edu or Jade Spaulding, at xxxx@,ilstu.edu. Any questions regarding your rights as a research participant or research-related injuries may be directed to ISU's Office of Research Ethics and Compliance (309) 438-2529.

Please do not share the purpose or expectations of this study with other classmates, as we may continue to do research in the future. Thank you again for your participation! Good luck with the rest of your semester! 